\title{
Daily Habits and Energy Consumption: Go to Bed Earlier for Environmental Protection
}

\author{
Shigeru Matsumoto ${ }^{1}$
}

\begin{abstract}
Energy consumption reduction in the residential sector is crucial for mitigating global warming. This has prompted researchers to investigate the determinants of household energy consumption from various aspects. However, previous studies have not examined the impact of time allocation on energy consumption, primarily because of the lack of surveys that simultaneously examine time allocation and energy consumption. We conducted an original survey of 547 Japanese households to examine whether time allocation affects their electricity consumption. We divided a 48-hour period into 192 time slots and asked the households to choose one of the 20 types of actions listed for each slot. We also collected information on the socioeconomic background and electricity consumption of the households. After controlling for various factors that affect household electricity consumption, we examined whether time allocation determines electricity consumption. The empirical result of our study revealed that while a married male's bedtime does not affect electricity consumption, a married female's bedtime does. This suggests that it is essential to understand the daily habits of consumers for proposing effective energy conservation measures.
\end{abstract}

Keywords: Electricity Usage, Household, Time Allocation

\section{Introduction}

The residential sector accounts for a large share in the end use of energy in modern society. In 2015, the residential sector held a 25.4\% share in energy usage in EU28, the second largest after the transportation sector (Eurostat 2018). Although the share of the residential sector in energy usage is much smaller, it still accounted for $14.3 \%$ in 2014 (Agency for Natural Resources and Energy of Japan 2016). Several developed countries have made a great leap forward in conserving energy in the industrial sector over the last decade. However, this achievement was not mirrored in the residential sector. In EU-28, the final energy consumption of the industrial sector fell by $15.5 \%$ and that of the residential sector declined by a mere 3.9\% between 2007 and 2015 (Eurostat 2018). In Japan, conversely, the final energy consumption of the residential sector doubled and that of the industrial sector increased only 0.8 times between 1973 and 2014 (Agency for Natural Resources and Energy of Japan 2016). These trends suggest that energy conservation in the residential sector is a pressing policy issue.

A literature review of energy conservation policies revealed that previous policies primarily focused on the diffusion of energy-efficient products. Many governments directed producers to improve the energy efficiency of their products and put in place systems to keep consumers informed about the energy efficiency of products. As a result, energy efficiency of products sold in the market improved notably, and, considering the difference in energy consumption, consumers started to choose more energy-efficient products. Despite this technological progress, households' energy 
savings have been very modest.

Households are concerned about the expenditure on energy services over a period of time. However, they do not give much thought to the amount of energy used by a specific home appliance. More than 150 years ago, Jevons (1865) asserted that the demand for resources will increase with gradual improvements in their efficiency in using that resource. Furthermore, Khazzoom (1980) argued that energy efficiency increases the stock and utilization of all home appliances. If there is a potential demand for energy services, energy efficiency improvements may not result in reduced entire household's energy consumption. Therefore, to assess the impact of improvement in energy efficiency, we need to know the potential demand for various services.

During times when electricity was not available, people performed specific activities at specific times. Today, however, we have the flexibility to plan various activities as per our convenience. A typical working class individual tends to spend much time outside his or her home and complete household activities in the night. The nighttime shift of household activities appears to affect energy consumption as additional energy is utilized for lighting or heating. Therefore, we expect that a nighttime shift of household activities increases electricity consumption. However, existing studies have not focused on the relationship between time allocation and energy consumption. This paper is aimed at analyzing this relationship through a household survey conducted in Japan.

The remainder of the paper is organized as follows. In Section 2, we briefly review the studies that evaluate the determinants of household energy usage. In Section 3, we summarize the data from our household survey. Section 4 presents the estimation model and reports the empirical findings, and Section 5 concludes the study.

\section{Brief Literature Review}

Frederiks et al. (2015) reviewed studies that evaluated the determinants of household energy usage and reported that sociodemographic (e.g., income, employment status, dwelling type/size, home ownership, household size, and stage of family life cycle) and psychological factors (e.g., beliefs and attitudes, motives and intentions, perceived behavioral control, cost-benefit appraisals, and personal and social norms) affect household energy usage. However, the impact of both these factors varies widely across studies (Urban and Ščasný 2012).

Almost all studies provide consistent results involving economies of scale in energy usage, stating that electricity usage decreases when the number of family members increase (O’Neill and Chen 2002; Druckman and Jackson 2008; Brounen et al. 2012). This is because family members can share certain energy services. Previous studies also found a positive relationship between income and energy usage. Although energy consumption increases with growth in income, the share of energy expenditure in the total household expenditure decreases. Therefore, the welfare impact of changes in energy prices varies among income classes (Romero-Jordán et al. 2016; Schulte and Heindl 2017). Similarly, most studies found a positive relationship between housing size and energy usage, stating that people living in large houses generally use more energy for daily activities.

Previous studies did not provide consistent results on the impact of education on energy 
consumption. Although Poortinga et al. (2004) and Nair et al. (2010) found that the educational background influences energy efficiency investments and/or energy-saving practices of individuals, Ritchie et al. (1981) and Gatersleben et al. (2002) did not find similar results.

Similarly, no consistent conclusion with respect to the impact of age on energy consumption was found in previous studies. Fritzsche (1981) analyzed the Consumer Expenditure Survey of US households and reported that an inverted u-shaped curve was found, with energy expenditure being the lowest during the early and late stages of the life cycle. Young people consume more energy because they are active, while elderly people use more energy because they stay home for longer hours. More recent studies, such as those by Brounen et al. (2012), Longhi (2015), and Gram-Hanssen (2013), found that age impacts every energy carrier differently. They found that gas consumption is largely determined by the dwelling conditions, but electricity consumption is less affected by the socioeconomics characteristics of households.

Hori et al. (2013) surveyed five Asian cities and found that the environmental attitudes of subjects influenced their curtailment behavior. In contrast, Trotta (2018) analyzed survey data from Britain and reported that environmental attitudes affect curtailment behavior and small-scale energy-efficient investment decisions but does not impact large-scale energy-efficient investment decisions. Wang et al. (2011) found that social interactions affected the energy-efficient investment decisions in Chinese households. Finally, Nakamura (2013) studied the curtailment behavior of Japanese households after the 2011 earthquake and found that social interaction impacted this behavior.

\section{Data}

The data used in this study were sourced from an Internet survey firm, Nippon Research Center ${ }^{1}$, and the survey was conducted on October 15-16, 2015. Since we expected time allocation to significantly differ between single and married individuals, we focused on married individuals between ages 25 and 64. A total of 546 responses were collected. We allocated respondents in advance to eliminate gender and age bias. Table 1 classifies the respondents. The survey's target area was the Tokyo metropolitan area, and the number of respondents by prefecture was 2, Ibaraki Prefecture; 86, Saitama Prefecture; 85, Chiba Prefecture; 239, Tokyo Special Ward; and 134, Kanagawa Prefecture.

Table 1. Age and Gender of Survey Respondents

\begin{tabular}{lrrrr} 
Age category & \multicolumn{2}{c}{ Male } & \multicolumn{2}{c}{ Female } \\
& Number & \multicolumn{1}{c}{ Share } & Number & \multicolumn{1}{c}{ Share } \\
\hline $25-34$ & 55 & $21.0 \%$ & 73 & $25.7 \%$ \\
$35-44$ & 69 & $26.3 \%$ & 69 & $24.3 \%$ \\
$45-54$ & 66 & $25.2 \%$ & 70 & $24.6 \%$ \\
$55-64$ & 72 & $27.5 \%$ & 72 & $25.4 \%$ \\
\hline Total & 262 & $100.0 \%$ & 284 & $100.0 \%$
\end{tabular}

${ }^{1}$ NRC, a full-service marketing research agency established in 1960, engages in consumer marketing and consultation, as well as academic and public opinion polling. 
We asked the married couples participating in the survey to maintain a daily record of their activities for two sampling days. We adopted the pre-coded method used in The Survey on Time Use and Leisure Activity, the national survey of the Japanese government. ${ }^{2}$ We divided two successive days (a 48-hour study period) into 192 (48 h $\times$ 4) time slots with 15-minute increments and asked the participants to choose the behavior of each slot from the following preset actions: (1) sleeping, (2) personal care, (3) consuming meals, (4) commuting, (5) working, (6) schooling, (7) housework, (8) nursing, (9) childcare, (10) shopping, (11) commuting, (12) watching television/reading newspaper, (13) relaxing, (14) self-development, (15) undertaking hobbies, (16) playing sports, (17) volunteering, (18) companionship, (19) medical treatment, and (20) others.

Table 2 presents the amount of time that husbands and wives allocated to the 20 activities on average. We classified the activities into two broad categories: outdoor and indoor. ${ }^{3}$ We expect the electricity usage to decrease with increase in the time spent on outdoor activities.

\begin{tabular}{|c|c|c|c|c|}
\hline & \multicolumn{2}{|c|}{ Husband $(\mathrm{N}=546)$} & \multicolumn{2}{|c|}{ Wife $(N=546)$} \\
\hline & Average & $\begin{array}{l}\text { Standard } \\
\text { Deviation }\end{array}$ & Average & $\begin{array}{l}\text { Standard } \\
\text { Deviation }\end{array}$ \\
\hline \multicolumn{5}{|l|}{ Outside activities } \\
\hline Commuting & 92.49 & 62.84 & 32.07 & 51.20 \\
\hline Movement & 24.85 & 52.23 & 32.06 & 49.61 \\
\hline Shopping & 8.91 & 22.46 & 34.86 & 36.09 \\
\hline Work & 479.12 & 199.81 & 168.06 & 210.41 \\
\hline School & 1.10 & 9.95 & 2.60 & 10.38 \\
\hline Sports & 5.43 & 22.55 & 6.36 & 23.79 \\
\hline Volunteer & 0.87 & 8.74 & 0.96 & 8.80 \\
\hline Companionship & 8.98 & 31.58 & 6.26 & 24.57 \\
\hline Medical treatment & 3.01 & 26.02 & 4.37 & 16.38 \\
\hline Sum & 624.75 & 206.65 & 287.61 & 229.70 \\
\hline \multicolumn{5}{|l|}{ Inside activities } \\
\hline Sleeping & 415.59 & 73.80 & 424.00 & 76.81 \\
\hline Television/newspaper & 85.65 & 101.36 & 119.07 & 117.39 \\
\hline Housework & 13.91 & 42.73 & 194.30 & 146.38 \\
\hline Personal care & 73.82 & 65.44 & 93.52 & 87.05 \\
\hline Relaxation & 71.21 & 77.40 & 103.83 & 98.15 \\
\hline Nurse & 0.52 & 4.56 & 2.25 & 10.46 \\
\hline Childcare & 8.48 & 37.61 & 51.44 & 118.68 \\
\hline Meal & 97.76 & 44.02 & 96.91 & 35.84 \\
\hline Self-development & 7.05 & 31.92 & 7.90 & 33.87 \\
\hline Hobby & 24.08 & 61.71 & 35.63 & 75.73 \\
\hline Others & 17.18 & 67.14 & 23.54 & 53.20 \\
\hline Sum & 815.25 & 206.65 & 1152.39 & 229.70 \\
\hline $\begin{array}{l}\text { Night time activities between } \\
23: 00 \mathrm{pm} \text { and } 4: 00 \mathrm{am}\end{array}$ & 54.01 & 58.94 & 45.48 & 52.53 \\
\hline
\end{tabular}

Table 2 shows that husbands spent 624.75 minutes and wives spent 287.61 minutes outdoors on average. In addition to the 479.12 minutes for work, husbands spent 92.49 minutes on commuting. Although wives spent only 168.06 minutes working on average,

2 The Survey on Time Use and Leisure Activities is aimed at obtaining comprehensive data on daily patterns of time allocation and leisure activities. The survey has been conducted every five years since 1976 (Statistics Bureau of Japan 2006).

3 This classification is not exact. Meals include lunch time taken at work. Although some childcare activities such as bringing children to parks are outdoor activities, childcare is categorized as an indoor activity. 
they were responsible for most of the shopping. As the survey was conducted on weekdays, husbands and wives spent a small amount of time on other outdoor activities. With respect to indoor activities, husbands and wives slept for about 7 hours and spent 1.6 hours on meals. The table reveals that wives spent more time on personal care and took longer breaks than husbands. However, wives spent much more time on household production activities, such as housework and childcare, than husbands.

In summary, the table indicates that husbands and wives allocate time very differently. Husbands spend much more time on job-related activities, and wives spend more time on household production.

\begin{tabular}{|c|c|c|c|}
\hline Variable & Unit & $\begin{array}{l}\text { Mean or } \\
\text { Share }\end{array}$ & $\begin{array}{l}\text { Standard } \\
\text { Deviation }\end{array}$ \\
\hline \multicolumn{4}{|l|}{ Sampling period } \\
\hline Metered in September & dummy & 0.58 & \\
\hline \multicolumn{4}{|l|}{ Electricity usage } \\
\hline Electricity usage of household & $\mathrm{kWh}$ & 9.00 & 4.72 \\
\hline Electricity usage per person & $\mathrm{kWh}$ & 3.20 & 1.90 \\
\hline \multicolumn{4}{|l|}{ Characteristics of household } \\
\hline Number of persons in family & person & 3.05 & 0.99 \\
\hline Age of household head & years & 46.97 & 11.13 \\
\hline College husband & dummy & 0.72 & \\
\hline College husband & dummy & 0.41 & \\
\hline Presence of young person (13-22) & dummy & 0.31 & \\
\hline Presence of elderly pers on $(>65)$ & dummy & 0.06 & \\
\hline Household income & million yen & 787.69 & 668.62 \\
\hline Deposit & million yen & 1656.44 & 3178.18 \\
\hline Loan & million yen & 921.57 & 1637.28 \\
\hline \multicolumn{4}{|l|}{ Characteristics of houses } \\
\hline Floor & $\mathrm{m}^{2}$ & 85.35 & 38.43 \\
\hline Housing tenure & dummy & 0.72 & 0.45 \\
\hline Detached house & dummy & 0.42 & 0.49 \\
\hline Woodhouse & dummy & 0.39 & 0.49 \\
\hline Old house (built before 2000) & dummy & 0.49 & 0.50 \\
\hline \multicolumn{4}{|l|}{ Appliance ownership and usage } \\
\hline Ampere & ampere & 38.50 & 7.98 \\
\hline Number of ACs & unit & 2.63 & 1.32 \\
\hline Size of the main AC & $\mathrm{m}^{2}$ & 17.41 & 5.16 \\
\hline Intensity of use of the main $\mathrm{AC}$ & rarely 1 - always 3 & 2.65 & 0.93 \\
\hline Ownership of cloth dryer & dummy & 0.49 & \\
\hline Ownership of dish washer & dummy & 0.32 & \\
\hline
\end{tabular}

The descriptive statistics of the variables used in the following analysis are listed in Table 3. Tokyo Electric Power Company Holdings bills households in the Tokyo metropolitan area every month. In this survey, we asked participants to enter their billing information. Approximately $58 \%$ of the respondents entered information concerning the September metering, while the remaining $42 \%$ entered information on the October metering. We initially calculated the daily electricity usage of households by dividing monthly usage by number of usage days. According to our calculations, a household uses $9.00 \mathrm{kWh}$ of electricity on average per day. We then calculated electricity usage per person per day by dividing daily electricity usage by number of members in a family. In this calculation, we excluded family members who live away from home for work, school, and clinical 
reasons. Figure 1 contains the distribution of electricity usage per person per day. According to our calculations the mean electricity consumption was $3.20 \mathrm{kWh}$ per person per day.

Our main hypothesis is that a person undertaking more activities at nighttime uses more energy. To test this hypothesis, we included the amount of active time from 23:00 pm to 4:00 am for the two sampling days. Although we cannot precisely gauge a subject's lifestyle from their bedtime in the sampling days, we can examine if nighttime activities increase energy consumption.

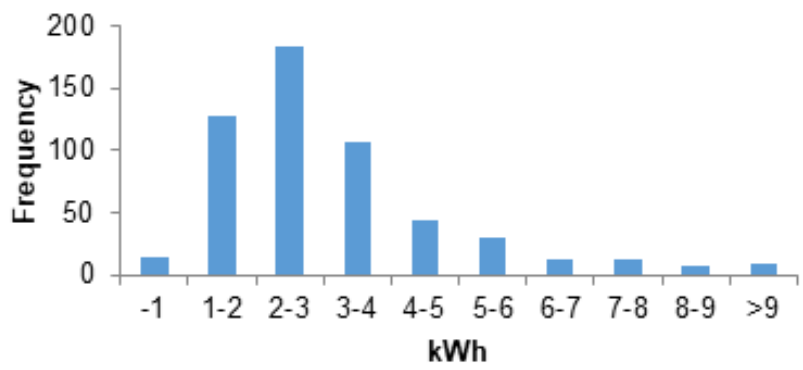

Figure 1. Electricity usage per person per day

We also included the household characteristics that previous studies found to affect household electricity usage. We first took account of the size of the families. As presented in Table 3, each family had 3.05 members on average. In the survey, we asked the respondents about their educational background and found that $72 \%$ of the husbands and $41 \%$ of the wives had attended a university. The share of college graduates in our survey is higher than the national average because our sampling area is within the metropolitan region. In our data, 31\% of the households included young people between ages 13 and 22, and 6\% of the households included elderly people over 65 years of age. The annual household income obtained from this survey was 7.88 million yen, which is higher than the average annual income of the Tokyo metropolitan area of 6.06 million yen (Ministry of Health, Labour and Welfare 2016), probably because our survey focused on households with married couples. Matsumoto (2016a) reports that the level of household saving determines the appliance ownership. In the survey, we asked respondents about their deposits and loans.

Families using many appliances at the same time require a high ampere rate. We asked households about their contract ampere and included their responses in the following analysis to control for the appliance ownership effect. The number of contract amperes in our survey was 38.50 on average. We also took account of the ownership of air conditioners (ACs), cloth dryers, and dishwashers. According to Matsumoto's (2016b) conditional demand analysis, the ownership of these appliances affects the electricity usage of households. We also took into account the number, size, and usage of ACs. Table 3 reveals that while each household owned 2.65 AC units on average, only $49 \%$ of households owned cloth dryers and $32 \%$ owned dishwashers.

Previous studies reported that the characteristics of housing affect energy usage. In this study, we asked participants about floor size, ownership, type, make, and year of 
construction. The floor area of the average house was $83.35 \mathrm{~m}^{2}$. Approximately $72 \%$ of respondents owned their houses, $42 \%$ lived in detached houses, $39 \%$ lived in houses made of wood, and $49 \%$ lived in houses constructed before 2000 .

\section{Empirical Model and Result}

To evaluate the impact of nighttime activity, we estimated the following semi$\log$ electricity demand function:

$$
\begin{aligned}
& \ln y_{i}=\alpha+\alpha_{S E P} S E P_{i}+\sum_{k} \beta_{k} x_{k i}+\sum_{l} \gamma_{l} h_{l i}+\alpha_{A M P} A M P_{i}+\sum_{m} \eta_{m} z_{m i} \\
& +\sum_{s} \theta_{S} \ln t_{s i}+\sum_{p} \lambda_{p} p_{i}+\varepsilon_{i}
\end{aligned}
$$

Here, $y_{i}$ is the per capita, per day electricity consumption of household $i, S E P_{i}$ is the dummy variable for the September metering, and $A M P_{i}$ is the number of contract amperes. Following the specifications of previous studies, we include household characteristic variable $x$, housing characteristic variable $h$, and appliance condition variable $z$. Our main variable, $t_{s}$, measures the nighttime activity time of spouse $s$. We include prefecture dummies $p$ to consider the prefecture fixed effect. The last term $\varepsilon_{i}$ is an error term.

The estimation result is presented in Table 4. The dummy variable for the September metering becomes positive and statistically significant, suggesting that households use more energy in the September metering period than in the October metering period. Several household characteristic variables become statistically significant. The number of members in a family becomes negative and significant. Since the dependent variable is the electricity consumption per person per day, the result implies that economies of scale exist in household energy usage. We also confirmed that the age composition of a household affects electricity usage. Specifically, electricity usage increases as the age of the household head increases. The presence of young or senior members in a family also increases electricity consumption. Education level was not found to meaningfully affect electricity usage. Furthermore, we found that income did not affect household electricity usage but wealth did. Households with large deposits were found to use less electricity. Since the age of the household head is controlled for, we expect this variable to serve as a behavior variable. The above results imply that thrifty households also save energy.

We found that living in a large house results in more electricity consumption. According to our estimations, a $1 \%$ increase in the house size raises electricity usage by $0.145 \%$. Although some previous studies reported that owners and renters behave differently, we did not observe any difference in the electricity usage of these two groups. We also found that individuals living in wooden buildings consumed less electricity.

The contract ampere variable becomes positive and significant. As mentioned before, households using many appliances at the same time need a high contract ampere. Therefore, the variable of contract ampere gauges the number of home appliances owned and the result suggests that households having many appliances consume more electricity. We also obtained the expected results for a series of AC variables. As the number of ACs increases, electricity consumption goes up. This effect is magnified if households use large ACs frequently. We found that the ownership of cloth dryers increases electricity consumption but that of dishwashers does not. 
We included the total occupied time in the analysis. ${ }^{4}$ Although we obtained the expected positive sign for this variable, it did not become statistically significant. Finally, the variable of wives' nighttime activity became significant, while that of husbands' did not. Hence, only wives' nighttime activity is associated with electricity usage. This difference is explained by the fact that wives still undertake most of the household work in Japanese households, a conclusion supported by the results in Table 2. Table 4 shows that a 1\% increase in wives' nighttime activity increases electricity usage by $0.033 \%$. Based on this estimation, reducing nighttime activity by an hour would decrease electricity consumption in an average size household by $0.14 \mathrm{kWh}(=(60 / 45.48) \times 0.033 \times 3.12)$ per day. Since an average household uses about $8.99 \mathrm{kWh}$ of electricity per day, approximately $1.51 \%$ of the daily electricity usage can be saved by advancing the bed time by an hour.

Table 4. Determinants of household energy consumption

\begin{tabular}{|c|c|c|}
\hline & Coefficient & Standard error \\
\hline Constant & -0.452 & $(0.373)$ \\
\hline \multicolumn{3}{|l|}{ Sampling period } \\
\hline Metered in September & $0.115^{4 * *}$ & $(0.036)$ \\
\hline \multicolumn{3}{|l|}{ Characteristics of household } \\
\hline Number of persons in family & $-0.277^{* * *}$ & $(0.023)$ \\
\hline Age of household head & $0.009^{* 4 *}$ & $(0.002)$ \\
\hline Presence of young person & $0.071^{* *}$ & $(0.032)$ \\
\hline Presence of el derly person & $0.148^{* *}$ & $(0.073)$ \\
\hline College husband & -0.051 & $(0.041)$ \\
\hline College wife & -0.036 & $(0.040)$ \\
\hline Log of household income & 0.043 & $(0.031)$ \\
\hline Log of hous ehold deposit & $-0.029^{* * *}$ & $(0.009)$ \\
\hline Logo of household loan & -0.007 & $(0.006)$ \\
\hline \multicolumn{3}{|l|}{ Characteristics of house } \\
\hline Log of floor area & $0.145^{*}$ & $(0.078)$ \\
\hline Housing tenure & -0.057 & $(0.053)$ \\
\hline Detached house & 0.115 & $(0.095)$ \\
\hline Woodhouse & $-0.187^{* *}$ & $(0.079)$ \\
\hline Old house & -0.044 & $(0.039)$ \\
\hline \multicolumn{3}{|l|}{ Appliance ownership and usage } \\
\hline Contract ampere & $0.005^{* *}$ & $(0.002)$ \\
\hline Number of ACs & $0.082^{* * *}$ & $(0.020)$ \\
\hline Size of the main AC & $0.005^{*}$ & $(0.003)$ \\
\hline Intensity of use of the main $\mathrm{AC}$ & $0.115^{* 4 *}$ & $(0.019)$ \\
\hline Ownership of cloth dryer & $0.110^{*+*}$ & $(0.041)$ \\
\hline Ownership of dish washer & 0.030 & $(0.046)$ \\
\hline \multicolumn{3}{|l|}{ Time allocation } \\
\hline Total occupied time & 0.007 & $(0.006)$ \\
\hline Husband nighttime activity & -0.004 & $(0.011)$ \\
\hline Wife nighttime activity & $0.033^{4 * *}$ & $(0.012)$ \\
\hline Adjusted $\mathrm{R}^{2}$ & 0.447 & \\
\hline
\end{tabular}

${ }^{4}$ Total occupied time is the aggregate amount of time in which at least one family member is in the house. 


\section{Conclusion}

In this study, we surveyed 547 Japanese households to examine whether time allocation affects their electricity consumption. Our empirical result reveals that electricity consumption rises with an increase in wives' nighttime activity. Shifting the time of household work from day to night would increases household energy consumption. Many power companies reduced electricity charges for nighttime to equalize the usage of electricity. However, since such a discount encourages shifting housework to later in the evening, it may increase energy consumption. This study suggests that understanding the daily habits of people is necessary to propose effective energy conservation measures.

\section{Acknowledgements}

The author received financial support from the Japan Society for the Promotion of Science KAKENHI (Grant number: 26340119) and the Environment Research and Technology Development Fund (2-1707) of the Environmental Restoration and Conservation Agency of Japan.

\section{References}

Agency for Natural Resources and Energy of Japan. (2016). http://www.enecho.meti.go.jp/ about/whitepaper/2016html/ accessed 16/04/2018.

Brounen, D., Kok, N., and Quigley, J.M. (2012). Residential energy use and conservation: economics and demographics. European Economic Review, 56, 931-945.

Druckman, A. and Jackson, T. (2008). Household energy consumption in the UK: A highly geographically and socio-economically disaggregated model. Energy Policy 36, 3177-3192.

Eurostat. (2018). Consumption of Energy. http://ec.europa.eu/eurostat/statistics-explained/ index.php/Consumption_of_energy accessed 11/04/2018.

Fritzsche, D.J. (1981). An analysis of energy consumption patterns by stage of family life cycle. Journal of Marketing Research, 18, 227-232.

Gram-Hanssen, K. (2013). Efficient technologies or use behavior, which is the more important when reducing households' energy consumption. Energy Efficiency, 6, 447-457.

Hori, S., Kondo, K., Nogata, D., and Ben, H. (2013). The Determinants of Household Energy-Saving Behavior: Survey and Comparison in Five Major Asian Cities. Energy Policy, 52, 354-362.

Khazzoom, D.J. (1980).-Economic implications of mandated efficiency standards for household appliances. Energy Journal, 1, 21-40.

Longhi, S. (2015). Residential energy expenditures and the relevance of changes in household circumstances. Energy Economics, 49, 440-450.

Fritzsche, D.J. (1981). An analysis of energy consumption patterns by stage of family life cycle. Journal of Marketing Research, 18, 227-232.

Frederiks, E.R., Stenner, K., and Hobman, E.V. (2015). The socio-demographic and psychological predictors of residential energy consumption: a comprehensive review. Energies, 8, 573-609.

Gatersleben, B., Steg, L., and Vlek, C. (2002). Measurement and determinants of environmentally significant consumer behavior. Environmental Behavior, 34, 335-362.

Jevons, W.S. The Coal Question, 3rd edition. Augustus M. Kelley, New York; 1865 [1965].

O'Neill, B.C., and Chen, B.S. (2002). Demographic determinants of household energy use in the United States. Population and Development Review, 28, 53-88.

Matsumoto, S. (2016a). Household Income Structure and Electrical Appliance Ownership: Evidence from Japanese National Household Survey. International Journal of Energy Economics and Policy, 6 (1), 14-19. 
Matsumoto, S. (2016b). How do household characteristics affect appliance usage? application of conditional demand analysis to Japanese household data. Energy Policy, 94, 214-223.

Ministry of Health, Labour and Welfare. (2016). Basic Survey on Wage Structure.

Nakamura, H. (2013). Effects of Social Participation and the Emergence of Voluntary Social Interactions on Household Power-Saving Practices in Post-disaster Kanagawa, Japan. Energy Policy, 54, 397-403.

Nair, G., Gustavsson, L., and Mahapatra, K. (2010). Factors influencing energy efficiency investments in existing Swedish residential buildings. Energy Policy, 38, 2956-2963.

Poortinga, W., Steg, L., and Vlek, C. (2004). Values, environmental concern, and environmental behavior: a study into household energy use. Environment and Behavior, 36, 70-93.

Ritchie, B., McDougall, G., and Claxton, J. (1981). Complexities of household energy consumption and conservation. Journal of Consumer Research, 8, 233-242.

Romero-Jordán, D., del Río, P., and Peñasco, C. (2016). An analysis of the welfare and distributive implications of factors influencing household electricity consumption. Energy Policy, 88, 361-370.

Schulte, I. and Heindl, P. (2017). Price and income elasticities of residential energy demand in Germany. Energy Policy, 102, 512-528.

Statistics Bureau of Japan. (2016). Outline of the 2016 Survey on Time Use and Leisure Activities. www.stat.go.jp/english/data/shakai/ accessed 06/03/2018.

Trotta, G. (2018). Factors Affecting Energy-Saving Behaviours and Energy Efficiency Investments in British Households. Energy Policy, 114, 529-539.

Urban, J. and Ščasný, M. (2012). Exploring domestic energy-saving: the role of environmental concern and background variables. Energy Policy, 47, 69-80.

Wang, Z., Zhang, B., Yin, J., and Zhang, Y. (2011). Determinants and Policy Implications for Household Electricity-Saving Behaviour: Evidence from Beijing, China. Energy Policy, 39, 3550-3557. 